\title{
Bioprospective Potentiality of Essential Oil of Ocimum gratissimum Linn.-An Innovative Approach for Fruit Preservation
}

\author{
Pranab Giri \\ Dept. Of Botany, Dum Dum Motijheel College Kolkata: 700074
}

\begin{abstract}
Of late, it becomes a great problem to the cultivators for post harvest preservation of fruits because of their proneness to be attacked by different pathogens causing rot or other necrotic lesions on fruit surface reducing their luster and market value as well. The use of synthetic compound for post harvest preservation of fruits definitely has some drawbacks because of their permeability through rind which may cause severe health hazards upon consumption. In this regard, natural volatile compounds from plant resources in particular may have immense potentiality to act as a substitute for synthetic compounds which will be safer and eco friendly. In the present investigation some pathogenic isolates from some common fruit surfaces were tested to grow in presence of essential oil extracted from six species of Ocimum growing in our state. All the isolates show different degrees of growth inhibition in presence of essential oil of all six species. In this regard laudable performance was observed in case of O. gratissimum which is significantly higher than all other species. GC analyses of oil sample of this species reveal that the major compound in the oil is eugenol which is present in highest quantity (47.45\%) in comparison to other species. The authentic sample of eugenol though exhibit growth inhibition but its inhibitory action is synergistically enhanced by other compounds present in oil. Thus there is sufficient possibility to explore the potentiality of the essential oil of Ocimum gratissimum to use it as a bio preservative in connection with the abatement of the possibility of post harvest loss of edible fruits caused by different pathogenic microorganisms.
\end{abstract}

Keywords: essential oil, eugenol, post harvest storage of fruits, GC analyses of essential oil.

\section{Introduction}

Post harvest preservation during household storage of fruits is a very common problem to fruit growers because of their sensitivity to be attacked by different microorganisms available in domestic environment and the same may also be happened during cold storage as well causing a major quantitative loss of fruits leading to its impact on the economy of the marginal farmers, businessman, mediators etc. The same problem in reality is being confronted where fruits are purchased directly from the growers and conventionally preserved before selling in the market by Government entrepreneur with the view to catapult the profit level of the growers who used to sell their produce to brokers. A wide variety of chemicals are used for temporary extension of self life of fruits during their household and industrial storage. Such chemicals being pervaded through the rind streamlined into the biological system of human beings upon consumption. It persuades severe health hazards and sometime becomes responsible for serious illness. Therefore innocuous approach for fruit storage particularly in household sector is imperative and need based ones. Essential oils of plant origin have been applied by different workers as an all out effort for preservation of dried and fleshy fruits from bio deterioration (Sharma et. al. 2000). Not only that the addition of essential oil of MAPs (Medicinal and Aromatic Plants) as a tool to maintain the overall quality of fruits has been established (M. Serrano et. al. 2008 ). Such natural volatiles are most effective against fungi causing rot of fruits and vegetables as well ( Tripathy et. al. 2004). The volatile oils obtained from Thymus kotschyanus, Ocimum basilicum and Rosmarinus officinalis have been shown to be effective against fungal pathogen like Penicillium expansum and Botrytis cinerea on pear (J. Marandi et al 2011). The chemical composition of the essential oil of $O$. basilicum Linn. Var. pilosum (Willd.) Benth. has even been analyzed in relation to its in vitro antifungal activity (Zhang et. al. 2009). But scanty report is available on the effectiveness of the essential oil of Ocimum gratissimum on the growth of fruit rotting microorganisms and almost no report is available on the chemical composition of the essential oil which is apostolic to the inhibition of the growth of such organisms. Therefore present investigation was aimed to: i) isolate the organisms causing deterioration of fruits during post harvest storage. In this regard five rotten fruits like banana, apple, pear, orange and papaya were chosen as experimental material.

ii) Study the efficacy of volatile oil of six species of Ocimum on the growth inhibition of isolates.

iii) Correlate the constituents of essential oil with antimicrobial efficacy through phytochemical studies. 


\section{Materials and methods}

The microorganisms from the deteriorated fruit samples were isolated following $\mathrm{Hgcl}_{2}$ method. The isolates were numbered using specific code to identify their source and pure cultures of those were maintained by sub culturing at regular interval. That isolated organisms actually responsible to cause the typical deteriorative symptoms were confirmed following Koch's Postulates.

\section{Extraction of oil sample}

Essential oil sample was extracted from fresh leaves of different species of Ocimum following hydro distillation method using Clevenger's apparatus (Clevenger 1928). Petroleum ether was used as a solvent for extraction (b.p. $\left.40^{\circ}-60^{\circ} \mathrm{C}\right)$. The oil sample was anhydrate with $\mathrm{Na}_{2} \mathrm{So}_{4}(300 \mathrm{gm} / \mathrm{l})$.

\section{Evaluation of antibacterial and antifungal properties of essential oil}

It was determined through disc diffusion method. To determine the antifungal activity fungal inoculum in the form of spore suspension $\left(0.1 \mathrm{ml}\right.$ spore suspension; $\left.10^{5} \mathrm{CFU} / \mathrm{ml}\right)$ was applied on the surface of agar plate with glass spreader. Sterilized discs of $8 \mathrm{~mm}$ in diameter were placed on the solid agar surface after shocking them well in the respective oil sample. Plates with fungal inocula were incubated at $32^{\circ} \mathrm{C}$ temperature. The degree of inhibition was expressed in term of diameter of the halo zone developed surrounding the disc. The antibacterial activity was also measured in the similar method except overnight grown bacterial suspension $(0.1 \mathrm{ml})$ was spread on the solid agar medium. The bacterial cultures were incubated at $37^{\circ} \mathrm{C}$ temperature.

\section{GC analyses of oil sample and quantification of eugenol content}

GC analysis of oil samples of different species of Ocimum were made with the help of CE8000 top model chromatogram using liquid nitrogen as a carrier gas. The oven temperature of the chromatogram was raised from $60^{\circ} \mathrm{C}$ to $220^{\circ} \mathrm{C}$ at the rate of $5^{\circ} \mathrm{C} / \mathrm{min}$. The holding time of the final temperature in the oven was $10 \mathrm{~min}$. The injector and detector temperature was $220^{\circ} \mathrm{C}$ for each. The column used for GC analysis was DB-5 MS type of capillary column of $30 \mathrm{mt}$ length. The film thickness and internal diameter of the column was 25 Micrometer. The concentrated essential oil sample was diluted properly up to a particular concentration using n-hexane as a solvent and $1 \mu \mathrm{l}$ of diluted sample was injected into the chromatograms for analysis. The authentic sample was also diluted similarly and the same volume was injected into the column. The peak produced by authentic sample was compared to the peaks obtained from the test samples with respect to their retention time (RT) in order to the identification as well as qualification of the eugenol present in the oil sample (Fig1). To quantify the amount of eugenol in oil sample the following formulation was adopted:

$$
\text { MxA2x100 }
$$

$$
\mathrm{A} 1 \mathrm{xN}
$$

Where, $\mathrm{M}=$ Standard stock concentration (ppm)

$\mathrm{A} 1=$ Area of the standard authentic sample (obtained from chromatogram)

$\mathrm{A} 2=$ Area of the test sample (obtained from chromatogram)

$\mathrm{N}=$ Stock concentration of the test sample ( $\mathrm{ppm})$

\section{Statistical analyses}

The statistical analyses of the experimental data were made with the help of SPSS software for windows.

\section{Results and Discussions}

The antimicrobial activity of Ocimum is well established. The essential oil mainly present in the leaves has been perceived as a prime microbial compound. In India the genus is represented by six species (Banerjee, 1996) namely Ocimum tenuiflorum, O. gratissimum, O. americanum, $O$. kilimandscharicum, $O$. basilicum, $O$. adscendens. The economic denomination of all the species has been reported to be due to the antimicrobial principles present in the volatile oil. With the view to ascertain whether the essential oil derived from these species could be exploited for preservation of edible fruits, efforts have been made to test the growth inhibitory efficacy of the oils on the microorganisms isolated from fruits causing their deterioration during household and industrial storage.

In this regard organisms were isolated from the lesions of the fruits like banana, apple, pear orange and papaya. The isolates are coded for temporary identification respectively as BISO01, APISO02, PISO03, ORISO04, and PAISO05 (Table - 2).Among these isolates one isolate (PISO03) was fungal and remaining were bacterial. The study of growth inhibition of isolates following disc diffusion method reveals that the volatile oils of all species are inhibitory (Table - 1). One significant observation in this regard is that the oil of Ocimum gratissimum as such is the best performer in terms of growth inhibition in comparison to the oils of other species 
(Fig 3). The GC analysis of the oil sample of the best performer reveals that eugenol is the major compound in the essential oil which occurs in highest percentage (47.45\%) among all the species under study (Fig :1\&2), except $O$. kilimandscharicum where the said compound is absent (Fig 5); albeit the later exerting growth inhibition to a lesser extent. The authentic sample of eugenol when directly applied on the isolated test organisms, growth inhibition was observed substantiating the fact of growth inhibition of volatile oil due to the presence of eugenol. Not only that the degree of inhibition is also proportional to the concentration of eugenol. On the contrary, growth inhibition of test organisms in presence of the essential oil of $O$. kilimandscharicum despite of the absence of eugenol may be due to the heterogeneous assemblage of other inhibitory compounds present in it. Further investigation regarding the identity of the inhibitory compounds in such oil is essential. Though eugenol is inhibitory to the growth of test organisms but in all cases the suitability of oil rather than eugenol as growth inhibitor is noteworthy (Fig:4 ). It brings out that the better performance of eugenol in oil is synergistically enhanced by other compounds which are also inhibitory in nature.

Thus being the highest eugenol producer among the all species under consideration the essential oil of Ocimum gratissimum may be regarded to have sufficient potentiality to preserve fruit during long term storage. The crude oil may be prescribed for application over rind surface prior to its storage. Still the universality of the application of oil will be strengthened if extensive study on growth retardation could be done on different isolates collected from more other fruits. Nevertheless, one drawback is sustaining in relation to its application particularly on those fruits where the market value or acceptability solely depends on the aroma emerging out of the fruits because the aroma of the volatile oil itself may subside the originality of the aroma compounds present in the fruit. Surmounting this difficulty of course may be a different domain of research.

\begin{tabular}{|c|c|c|c|c|c|c|}
\hline \multirow{2}{*}{ Name of the species } & \multicolumn{5}{|c|}{ Isolates } & \multirow{8}{*}{$\begin{array}{l}\text { Diameter of } \\
\text { the } \\
\text { inhibition } \\
\text { zone }\end{array}$} \\
\hline & BISO01 & APISO02 & $\begin{array}{l}\text { PISO03 } \\
\text { (Fungus) }\end{array}$ & ORISO04 & PAISO05 & \\
\hline O.tenuiflorum & $8.3 \pm 0.13^{f}$ & $9.2 \pm 0.18^{\mathrm{e}}$ & $9.8 \pm 0.12^{b}$ & $8.6 \pm 0.08^{f}$ & $8.8 \pm 0.11^{\mathrm{f}}$ & \\
\hline O.gratissimum & $19.5 \pm 0.17^{\mathrm{a}}$ & $16.5 \pm 0.12^{a}$ & $15.5 \pm 0.11^{\mathrm{a}}$ & $19.8 \pm 0.11^{\mathrm{a}}$ & $17.5 \pm 0.14^{a}$ & \\
\hline O.americanum & $8.8 \pm 0.11^{\mathrm{e}}$ & $9.8 \pm 0.10^{\mathrm{c}}$ & $8.8 \pm 0.15^{\mathrm{e}}$ & $10.8 \pm 0.07^{\mathrm{b}}$ & $9.8 \pm 0.13^{d}$ & \\
\hline O.kilimandscharicum & $8.9 \pm 0.18^{\mathrm{d}}$ & $9.4 \pm 0.14^{\mathrm{d}}$ & $9.4 \pm 0.11^{\mathrm{d}}$ & $8.9 \pm 0.06^{\mathrm{e}}$ & $8.9 \pm 0.09^{\mathrm{e}}$ & \\
\hline O.basilicum & $11.6 \pm 0.12^{\mathrm{c}}$ & $8.6 \pm 0.11^{f}$ & $9.6 \pm 0.08^{c}$ & $10.6 \pm 0.16^{\mathrm{c}}$ & $11.6 \pm 0.08^{b}$ & \\
\hline o.adscendens & $12.4 \pm 0.09^{\mathrm{b}}$ & $10.4 \pm 0.09^{b}$ & $9.4 \pm 0.07^{\mathrm{d}}$ & $9.9 \pm 0.10^{\mathrm{d}}$ & $10.4 \pm 0.06^{\mathrm{c}}$ & \\
\hline
\end{tabular}

Table 1: Effect of volatile oil of different species of Ocimum on the growth of isolated organisms from different infected fruits.

\begin{tabular}{|c|c|c|}
\hline Fruit & Isolated Organism & Species of Ocimum used to taste antimicrobial efficacy \\
\hline Banana & BISO01 & \multirow{5}{*}{$\begin{array}{l}\text { Ocimum tenuiflorum } \\
\text { O.gratissimum } \\
\text { O. americanum } \\
\text { O. kilimandscharicum } \\
\text { O.basilicum } \\
\text { O. adscendens }\end{array}$} \\
\hline Apple & APISO02 & \\
\hline Pear & PISO03(Fungal) & \\
\hline Orange & ORISO04 & \\
\hline Papaya & PAISO05 & \\
\hline
\end{tabular}

Table 2: Name of different species of Ocimum, the essential oil of which are used to study the antimicrobial efficacy on the isolates from different edible fruits.

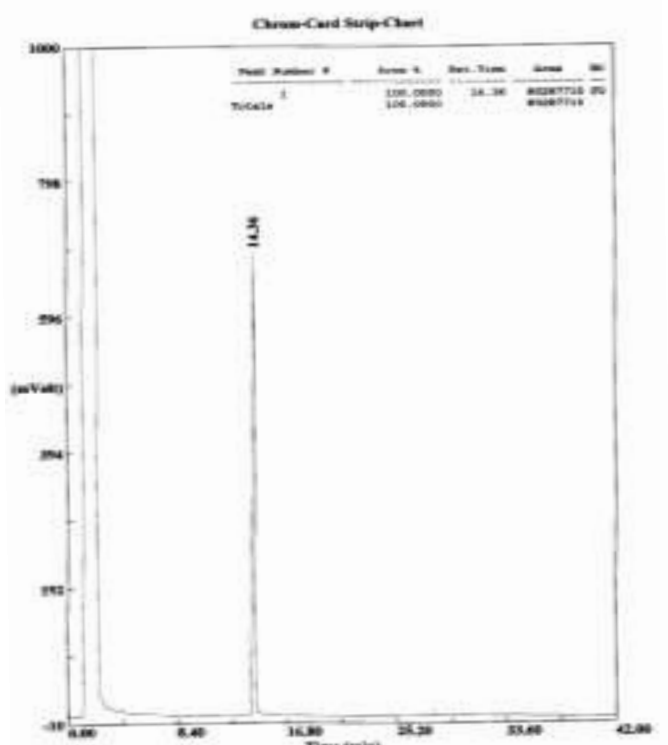

Fig 1 : Gas Liquid Chromatogram of the authentic sample of Eugenol. 


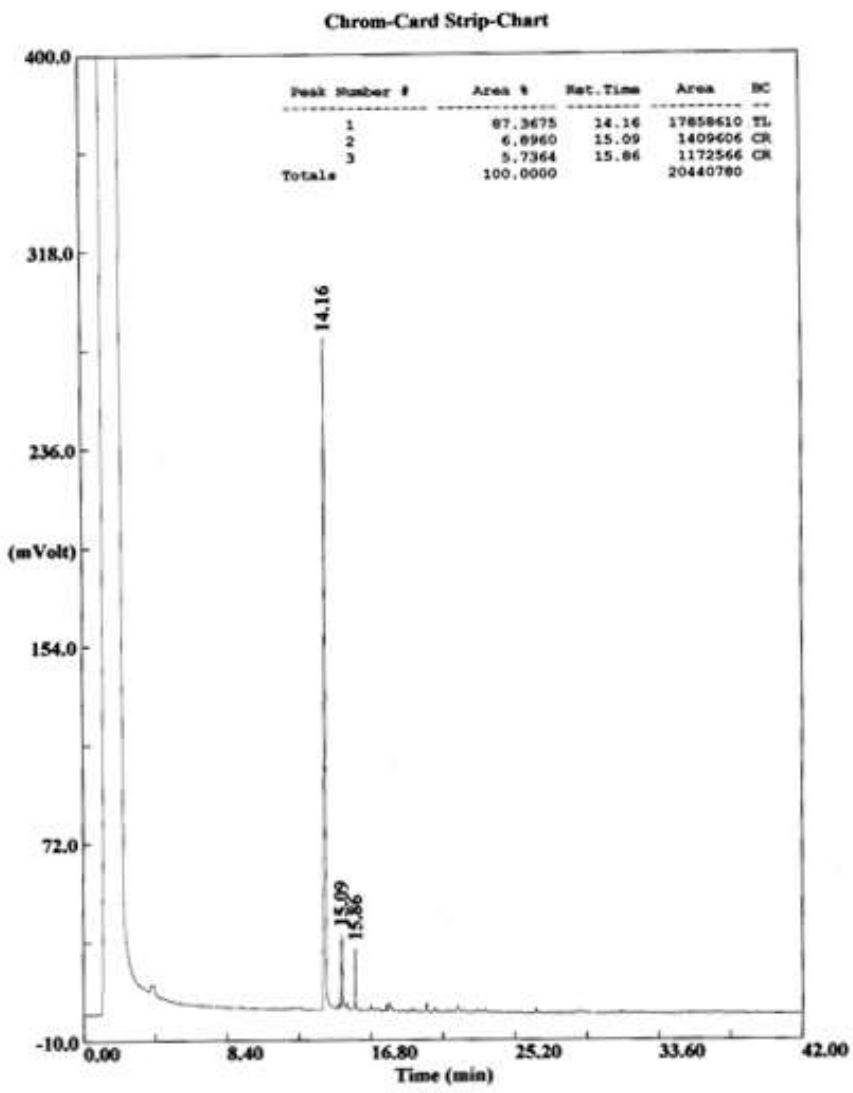

Fig 2: Gas Liquid Chromatogram of the essential oil obtained from O. gratissimum.

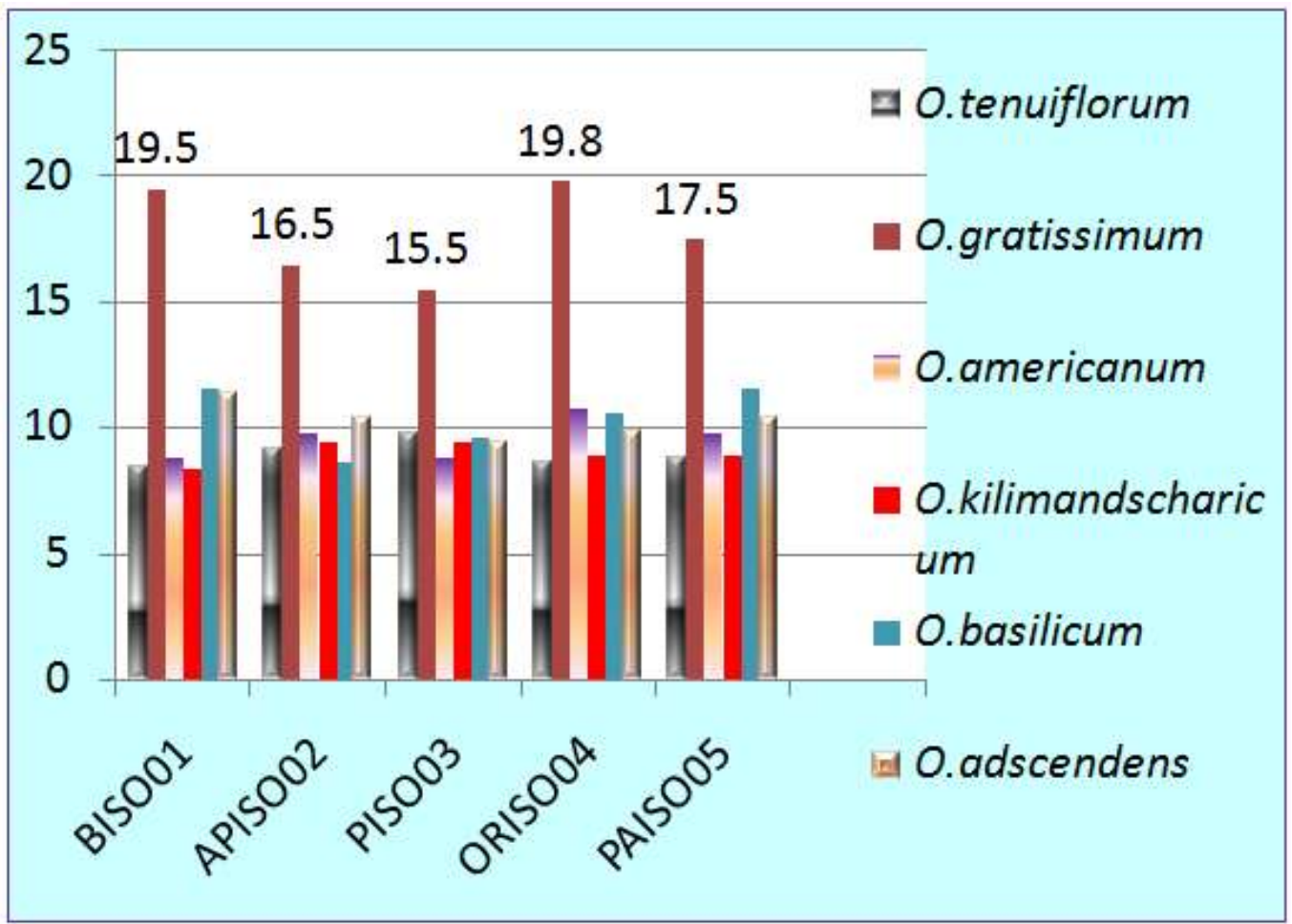

Fig3: Highest efficacy of growth inhibition of the essential oil of Ocimum gratissimum on the isolated organisms from deteriorated fruits. 

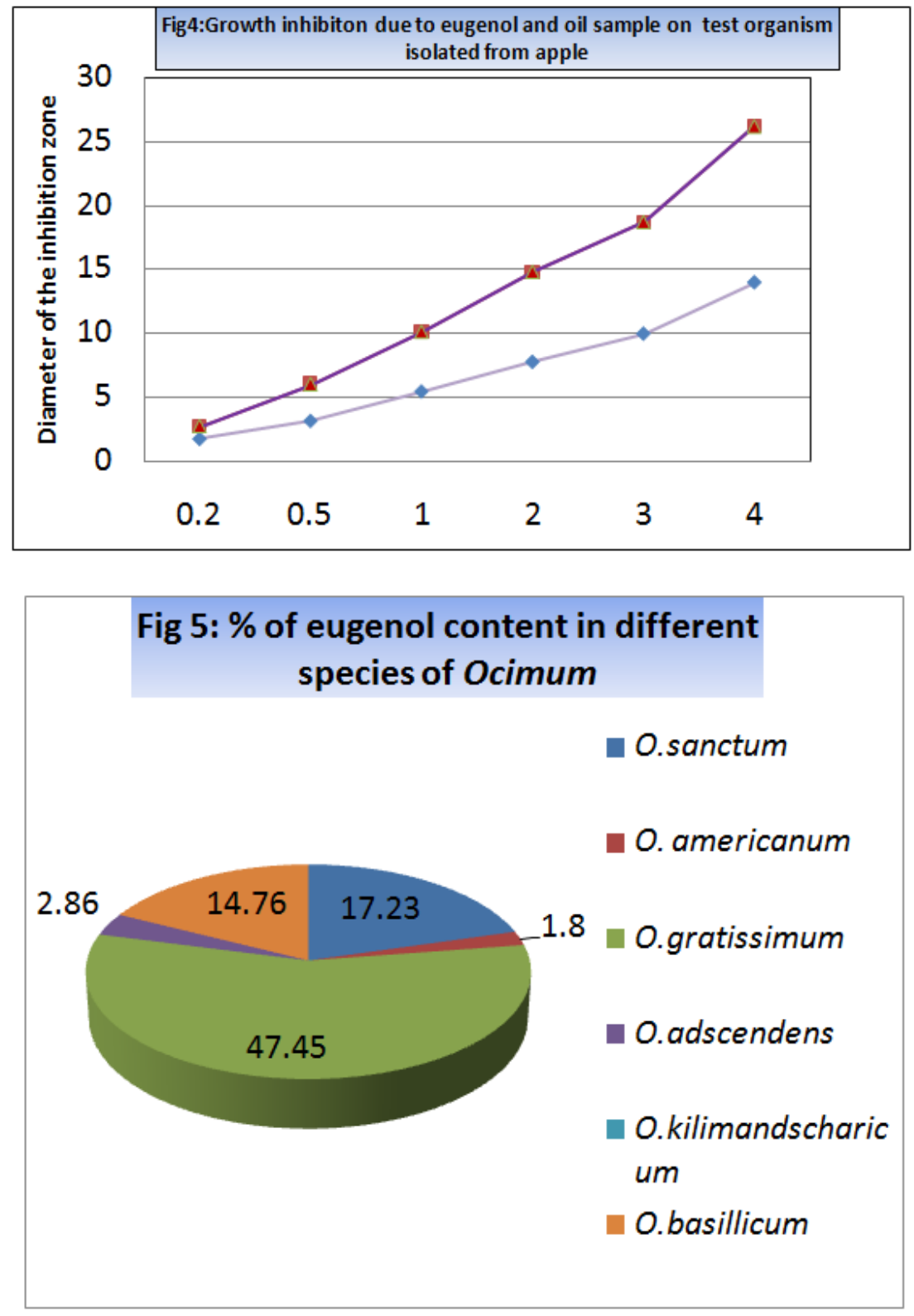

\section{References}

[1]. Clevenger, J.F., 1928. Approaches for determination of volatile oil, J. Ann. Pharm. Asso, 17:346.

[2]. Banerjee, S. 1996. Taxonomic Revision of some Genera of the Tribe Ocimoidae (Lamiaceae) of India. Ph.D. thesis, University of Kalyani, Kalyani, Nadia.

[3]. Sharma, N;Donahaye, E.J.;Nararro, S. and Leesch, J.C. [Eds](2001) Proc. Int. Conf. Controlled atmosphere and fumigation in stored products, Fresno, C.A. 29 Oct- 3 Nov,2000; Extensive Printing service, Clovis, CA, USA PP.Pg 195-208.

[4]. Tripathi, P.; Dubey, N.K.2004; Exploitation of natural products as an alternative strategy to control post harvest fungal rotting of fruits and vegetables; In :Post harvest Biology and Technology, Vol 32(3); Pg-235-245.

[5]. Serrano Maria et. al. 2008; The addition of essential oil to MAP as a tool to maintain the overall quantity of fruits; In : Trends in Food Science \& Technology; Vol 19, Issue 9 ;Pg 464-471.

[6]. Zhang, Shery-Kun, Wen-Ju-Wu 2009; The main chemical composition and In vitro antifungal activity of the essential oils of $O$. basilicum Linn. Var. pilosum ( Willd.) Benth; In : Molecules; 14(1); Pg 273-278.

[7]. Marandi, R.J.; Ghosta, Y.; Hassani, A. 2011;Control of Penicillium expansum and Botrytis cenerea on pear with Thymus kotschyanus, O. basilicum and Rosmarinus officinalis essential oil; In: Journal of Medicinal Plants Research; Vol. 5(4), Pg 626634 . 